\title{
Microphthalmia with linear skin defects syndrome (MLS): a male with a mosaic paracentric inversion of $X p$
}

\author{
K. Kutsche, ${ }^{a}$ W. Werner, ${ }^{b}$ O. Bartsch, ${ }^{b}$ A. von der Wense, ${ }^{c}$ P. Meinecke ${ }^{d}$ and \\ A. $\mathrm{Gal}^{\mathrm{a}}$ \\ a Institut für Humangenetik, Universitätsklinikum Hamburg-Eppendorf, Hamburg; \\ b Institut für Klinische Genetik, Medizinische Fakultät der Technischen Universität Dresden, Dresden; \\ ${ }^{\mathrm{c}}$ Abteilung für Neonatologie und pädiatrische Intensivmedizin, ${ }^{\mathrm{d}}$ Abteilung für Medizinische Genetik, \\ Altonaer Kinderkrankenhaus, Hamburg (Germany)
}

\begin{abstract}
The microphthalmia with linear skin defects syndrome (MLS) is an X-linked dominant disorder with male lethality. In the majority of the patients reported, the MLS syndrome is caused by segmental monosomy of the Xp22.3 region. To date, five male patients with MLS and 46,XX karyotype ("XX males") have been described. Here we report on the first male case with MLS and an XY complement. The patient showed agenesis of the corpus callosum, histiocytoid cardiomyopathy, and lactic acidosis but no microphthalmia, and carried a mosaic subtle inversion of the short arm of the $\mathrm{X}$ chromosome in $15 \%$ of his peripheral blood lymphocytes, 46, $Y, \operatorname{inv}(\mathrm{X})(\mathrm{p} 22.13 \sim 22.2 \mathrm{p} 22.32 \sim 22.33)[49] / 46, \mathrm{XY}[271]$.
\end{abstract} By fluorescence in situ hybridization (FISH), we showed that
YAC 225H10 spans the breakpoint in Xp22.3. End-sequencing and database analysis revealed a YAC insert of at least $416 \mathrm{~kb}$ containing the genes HCCS and AMELX, and exons 2-16 of ARHGAP6. Molecular cytogenetic data suggest that the Xp22.3 inversion breakpoint is located in intron 1 of ARHGAP6, the gene encoding the Rho GTPase activating protein 6 . Future molecular studies in karyotypically normal female MLS patients to detect submicroscopic rearrangements including the ARHGAP6 gene as well as mutation screening of ARHGAP6 in patients with no obvious chromosomal rearrangements will clarify the role of this gene in MLS syndrome.

Copyright $\odot 2002$ S. Karger AG, Basel
The microphthalmia with linear skin defects syndrome (MLS; MIM 309801) is a severe developmental disorder. Major clinical signs are localized dermal aplasia and microphthalmia. Occasional abnormalities include agenesis of the corpus callosum, sclerocornea, chorioretinal abnormalities, infantile seizures, congenital heart defect, and mental retardation. At least 30 patients have been described so far (Friedman et al., 1988; Al-Gazali et al., 1990; Donnenfeld et al., 1990; Temple et al., 1990; Allanson and Richter, 1991; Gericke et al., 1991; Thies et al., 1991; Lindor et al., 1992; Naritomi et al., 1992; Happle et al., 1993; Bird et al., 1994; Eng et al., 1994; Lindsay

Supported by a grant from the Foundation Fighting Blindness (USA). Received 30 October 2002; manuscript accepted 20 December 2002. W.W. and O.B. contributed equally to this work.

Request reprints from Kerstin Kutsche, PhD, Institut für Humangenetik Universitätsklinikum Hamburg-Eppendorf, Butenfeld 42 D-22529 Hamburg (Germany); telephone: +49 40428034597 fax: +49 4042803 5138; e-mail: kkutsche@uke.uni-hamburg.de et al., 1994; McLeod et al., 1994; Mücke et al., 1995; Camacho et al., 1997; Paulger et al., 1997; Cox et al., 1998; Ogata et al., 1998; Stratton et al., 1998; Zvulunov et al., 1998; Kono et al., 1999; Kayserili et al., 2001; Anguiano et al., 2003).

The MLS syndrome is considered to be an X-linked dominant male lethal disorder. Conventional and molecular cytogenetic studies of most MLS patients revealed an XX complement with a variety of X-chromosomal aberrations, including deletion of Xpter $\rightarrow$ p22 or unbalanced translocation between the $\mathrm{X}$ chromosome and an autosome or the $\mathrm{Y}$ chromosome, that all resulted in segmental monosomy of Xp22.3. Remarkably, four female patients with an apparently normal karyotype have also been described (Happle et al., 1993; Bird et al., 1994; Cox et al., 1998; Zvulunov et al., 1998) suggesting that submicroscopic rearrangements or "short length" mutations in a yet unidentified gene may also be responsible for the trait. To date, three affected males and twin brothers have been reported, all with an XX complement and a translocation between Xp and Yp (Lindsay et al., 1994; Paulger et al., 1997; Stratton et al., 1998; Kono et al., 1999; Anguiano et al., 2003). A sixth patient \begin{tabular}{lll}
\hline KARGER & $\begin{array}{l}\text { Fax }+41613061234 \\
\text { E-mail karger@karger.ch } \\
\text { www. }\end{array}$ & ( 2003 S. Karger AG, Basel \\
0301-0171/02/0994-0297\$19.50/0
\end{tabular}
Accessible online at: www. karger.com/cgr 
had ambiguous genitalia and a 46,XX karyotype (Camacho et al., 1997).

By mapping the breakpoints of MLS patients, an $\sim 570-\mathrm{kb}$ minimal region of monosomy has been identified in Xp22.3 (Wapenaar et al., 1993; 1994), distal to AMELX (amelogenin) (Lagerstrom et al., 1991), and cloned into overlapping cosmids (Cox et al., 1998). Three genes have been mapped and characterized in the critical deletion interval for MLS: MID1 (midline-1) mutated in the X-linked Opitz G/BBB syndrome (Quaderi et al., 1997), HCCS which encodes the human holocytochrome c-type synthetase (Schaefer et al., 1996), and ARHGAP6 encoding a Rho GTPase activating protein (Schaefer et al., 1997). Mice deficient for the Rho GAP domain of Arhgap6 did not show any detectable phenotypic or behavioural abnormalities (Prakash et al., 2000). In marked contrast, deletion of the Hccs gene in the mouse leads to lethality of the embryos early in development suggesting that loss of HCCS causes the male lethality of MLS syndrome (Prakash et al., 2002).

Another important factor in determining the MLS phenotype seems to be the pattern of $\mathrm{X}$ inactivation. It has been proposed that functional absence of the MLS gene caused by inactivation of the normal $\mathrm{X}$ chromosome in patients with Xp22 monosomy may play a critical role in the development of MLS (reviewed in Van den Veyver, 2001). Moreover, variable tissuespecific X-inactivation is likely to account both for the intrafamilial variability and clinical divergence in sporadic cases (Allanson and Richter, 1991; Ballabio and Andria, 1992; Mücke et al., 1995).

In this report, we describe the first case of MLS syndrome in a male with an XY complement and a mosaic paracentric inversion of the short arm of the $\mathrm{X}$ chromosome in blood lymphocytes.

\section{Materials and methods}

\section{Case report}

The male infant was born to non-consanguineous parents by Cesarean section the $36^{\text {th }}$ week of gestation. Ultrasound examination revealed intrauterine growth retardation. There was no history of prenatal drug exposure or intrauterine infection. At birth, the patient was noted to have bilateral paranasal linear skin defects but no microphthalmia. Birth weight was low $(1,620 \mathrm{~g},-3 \mathrm{SD})$ and a severe postnatal metabolic acidosis developed. Ultrasound investigations revealed lissencephaly and agenesis of the corpus callosum as well as pericardial effusion and mild hypertrophic cardiomyopathy. Blood pyruvate concentration was normal with markedly elevated blood (6$18 \mathrm{mmol} / 1$, normal $<2$ ) and CSF lactate values $(10.7 \mathrm{mmol} / 1$, normal $<1.5)$, and a slightly elevated alanine level $(8.5 \mathrm{mg} / \mathrm{dl}$, normal $<5.1)$. Lactic aciduria and ketonuria were present. Respiratory chain enzyme activities were in the normal range both in a muscle biopsy and in skin fibroblasts. The patient was treated symptomatically with bicarbonate buffer, a specific vitamin cocktail (containing carnitine, coenzyme Q, riboflavin, vitamin $\mathrm{K} 1$, and thiamine), and ketogenic diet without any obvious benefit. During follow-up studies, he showed failure to thrive, cardiomyopathy with supraventricular tachycardia and pericardial effusion, hepatic failure with cholestatic hepatopathy, and a deteriorating lactic acidosis. He died from multiple organ failures at the age of four months. Postmortem autopsy confirmed the agenesis of the corpus callosum and the severe liver disease with fatty degeneration and fibrosis. Histologic investigation of the heart showed histiocytoid/oncocytic cardiomyopathy and subendocardial myocardial necrosis.

Conventional cytogenetic and FISH studies

Chromosome preparations were made from PHA-stimulated peripheral blood lymphocytes. Cytogenetic analysis was carried out by an improved high-resolution RBG-H banding method (700-1,000 band level) (Werner and Spiegler, 1988). Fluorescence in situ hybridization was performed as previously described (Bartsch et al., 1999). DOP-PCR products of YAC 225H10 were labeled using tetramethylrhodamin-6-dUTP. Chromosomes were counterstained using DAPI (Roche) and mounted in antifading solution (Vector Labs). Slides were analyzed by Axiophot ${ }^{\mathrm{TM}}$ epifluorescence microscopes (Zeiss) and the ISIS ${ }^{\mathrm{TM}}$ digital imaging system (Meta Systems).

\section{Derivation of $Y A C$ end-sequences}

End-sequences of YAC clone $225 \mathrm{H} 10$ were obtained as described by Nehls et al. (1995). Briefly, total yeast DNA was isolated by standard protocols and digested with Sau3AI, HpaII, TaqI, HinPI, AluI, BstUI, HaeIII, RsaI, and NlaIII. DNA fragments were ligated to one of two vectorette "isoforms" and subsequently, end sequences were amplified selectively in primary and secondary PCR reactions. Purified amplicons (JETQUICK PCR purification kit, Genomed) were directly sequenced using the ABI Prism Dye Terminator Kit (PE Applied Biosystems) and the ABI Prism 377 automatic sequencer (PE Applied Biosystems).

\section{Results}

\section{Conventional and molecular cytogenetic studies}

Cytogenetic investigation of peripheral blood lymphocytes by high resolution RBG-H banding revealed two cell lines, one with an apparently normal $(46, \mathrm{XY})$ karyotype and a second one with an aberrant karyotype. The normal karyotype was observed in $271(\sim 85 \%)$ of the 320 metaphases analyzed (Fig. 1a, b). In 49 metaphases, an aberrant R-banding pattern was found at the telomeric part of the short arm of the $\mathrm{X}$ chromosome (Fig. 1a, c). A terminal or an interstitial deletion was unlikely for both the normal and rearranged $\mathrm{X}$ chromosomes had the same length. Fluorescence in situ hybridization (FISH) analysis with cosmid 34F5, containing exons $1-5$ of the SHOX gene located in the pseudoautosomal region (PAR), and with cosmid 2.1 , that maps about $1,700 \mathrm{~kb}$ proximal to $\mathrm{SHOX}$, yielded a single signal on the terminal end of the $\mathrm{X}$ chromosome in all metaphases analyzed (data not shown). Taking the cytogenetic and FISH data together, the rearrangement observed was interpreted as a paracentric inversion with the distal breakpoint in $\mathrm{Xp} 22.32 \sim \mathrm{p} 22.33$ and the proximal breakpoint in Xp22.13 p22.2, karyotype mos 46, $\mathrm{Y}, \operatorname{inv}(\mathrm{X})(\mathrm{p} 22.13 \sim 22.2 \mathrm{p} 22.32 \sim$ 22.33)/46,XY.

To map the putative inversion breakpoint in Xp22.3 more precisely, we performed FISH analysis with YAC clone $225 \mathrm{H} 10$, which contains part of the previously defined MLS critical region (Wapenaar et al., 1993) and which has been found to be deleted in three patients with MLS syndrome (Lindsay et al., 1994). In the majority of the 38 metaphases analyzed with YAC 225H10, we observed one distinct signal on the short arm of the X chromosome (Fig. 2a). However, in three metaphases, this YAC produced two signals of similar intensity (Fig. 2b), one in Xp22.3 and another one located more proximally, suggesting that this clone is bridging the breakpoint.

\section{YAC $225 H 10$ contains exons 2-16 of the ARHGAP6 gene in $X p 22.3$}

By using vectorette PCR, we determined the end-sequences of YAC 225H10 and initiated BLASTN database searches at the NCBI. YAC endmarker A was located at position 11,514 bp in BAC clone GS-602M16 (GenBank acc. no. AC003657) and 
Fig. 1. Mosaic paracentric inversion of the short arm of the $\mathrm{X}$ chromosome $[\operatorname{inv}(\mathrm{X})(\mathrm{p} 22.13 \sim 22.2 \mathrm{p} 22.32 \sim 22.33]$ in the patient with MLS syndrome. (a) Ideogram of a high resolution RBG-banded X chromosome. The upper arrow indicates the breakpoint in $\mathrm{Xp} 22.33 \sim \mathrm{p} 22.32$, whereas the lower one points to that in Xp22.2 p22.13. (b) Three RBG-H-banded normal $\mathrm{X}$ chromosomes and (c) three rearranged $\mathrm{X}$ chromosomes of the patient. The two short lines point to the centromere and the arrow in (c) marks the inverted region. a

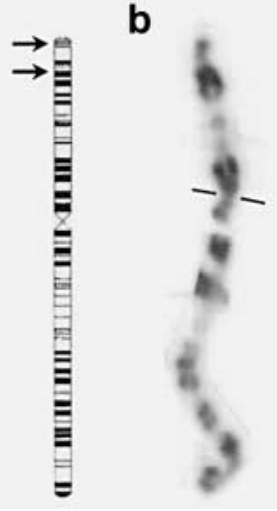

c

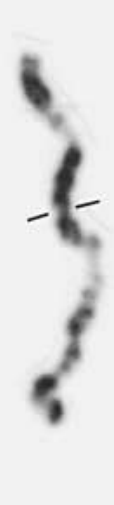

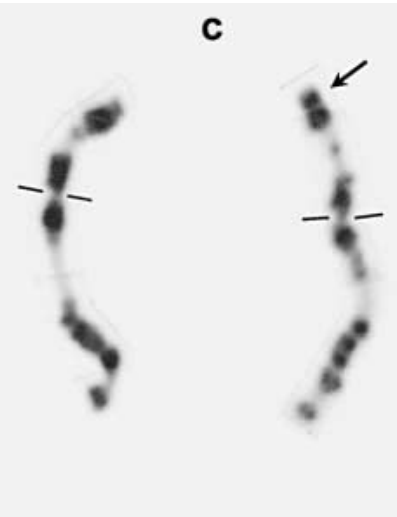
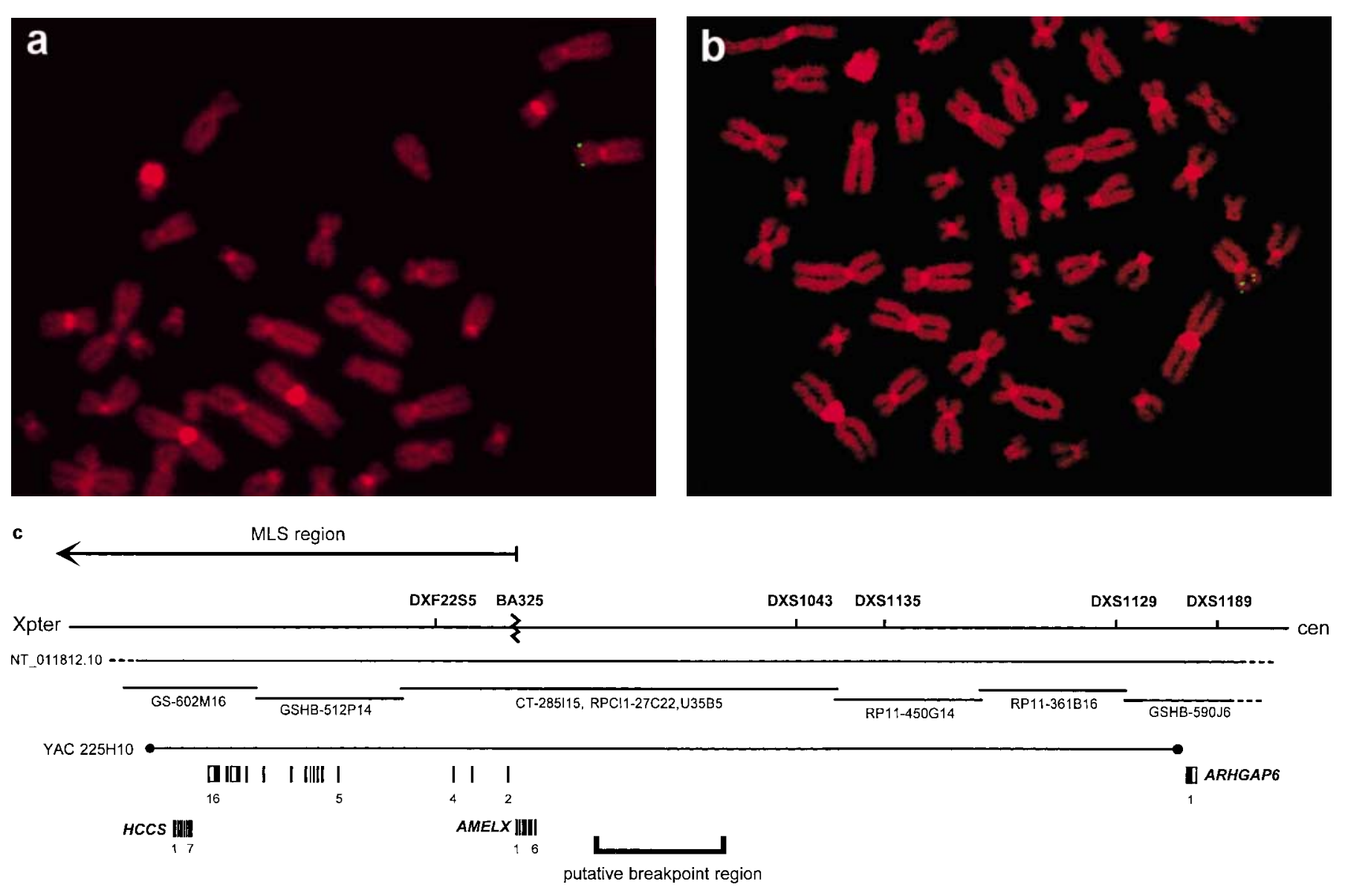

Fig. 2. Characterization of the inversion breakpoint in $\mathrm{Xp} 22.3$. (a, b) Fluorescence in situ hybridization with YAC clone $225 \mathrm{H} 10$ on metaphase spreads of the patient. (a) In the majority of the metaphases analyzed, YAC 225H10 gives one signal on the $\mathrm{X}$ chromosome. (b) In contrast, YAC $225 \mathrm{H} 10$ produces two signals in a small number of metaphases with the rearranged $\mathrm{X}$ chromosome of the patient. The probe is labeled by tetramethylrhodamin (depicted in green). Chromosomes are counterstained with DAPI (depicted in red). (c) Schematic representation of the critical breakpoint area in Xp22.3. The uppermost arrow indicates the proximal part of the critical region of the MLS syndrome. The second line represents a region in Xp22.3

in telomere (Xpter) to centromere (cen) orientation, that is not drawn to scale. Microsatellite marker loci and the deletion breakpoint of MLS patient BA325 (zigzag line), that defines the proximal boundary of the MLS critical region, are shown. Middle lines indicate genomic contig sequences and PAC, $\mathrm{BAC}$, or cosmid clones that are completely sequenced. The bottom line represents the insert of YAC 225H10. Below the YAC insert, exons of the genes ARHGAP6, HCCS, and AMELX are shown by thin vertical bars which are partially numbered. White boxes indicate untranslated regions of the ARHGAP6 gene. The bracket at the very bottom shows the putative breakpoint region in the patient. 
at position $4,255,725 \mathrm{bp}$ in human genome contig NT_011812.10 (Fig. 2c). We mapped YAC endmarker B to position 29,485 bp in clone GSHB-590J6 (GenBank acc. no. AC004554) and to position 4,821,848 bp in contig NT_011812.10 (Fig. 2c). Thus, an insert size of 566,123 bp was determined for YAC $225 \mathrm{H} 10$ that agreed well with the size of $560 \mathrm{~kb}$ estimated previously by PFGE analysis (Ferrero et al., 1995). By compiling recent data, we found three genes, HCCS, AMELX, and ARHGAP6, present on YAC 225H10, which contains the putative inversion breakpoint of the patient's rearrangement in Xp22.3 (Fig. 2c).

ARHGAP6 consists of 16 exons and spans a region of $528 \mathrm{~kb}$. With the exception of exon 1, that is located $373 \mathrm{~kb}$ centromeric to the previously designated first exon (currently exon 2), all exons of the ARHGAP6 gene are present on the insert of YAC 225H10. The fact that exon 1 of ARHGAP6 is not covered by the YAC bridging the putative breakpoint suggests that the ARHGAP6 gene is disrupted by the inversion in $\mathrm{Xp} 22.3$ in $\sim 15 \%$ of the patient's lymphocytes. Moreover, the equal intensities of the split signals obtained by FISH (Fig. 2b) suggest that the breakpoint is located approximately in the middle of the insert, i.e. in intron 1 of ARHGAP6 (Fig. 2c).

In an attempt to further characterize the breakpoint, we performed 3' RACE experiments on cDNA prepared from fibroblast RNA of the patient using a "forward" primer located in exon 1 of ARHGAP6 in combination with a polyT primer. Although we did several rounds of RACE-PCR, cloned the PCR products, and sequenced the inserts of about 70 clones, we failed to identify any aberrant ARHGAP6 transcript consisting of the first exon of ARHGAP6 fused to a sequence originating from the proximal inversion breakpoint in Xp22.13 p22.2 (data not shown). Possibly, the presence of the chromosomal inversion in only a distinct portion of the patient's cells has significantly hampered the identification of such aberrant fusion transcripts.

\section{Discussion}

In the present paper, we describe the first 46,XY male with MLS syndrome, who carries a mosaic of a paracentric inversion of Xp with one breakpoint in Xp22.32 p22.33 and the other one in Xp22.13 p22.2 in peripheral blood lymphocytes. In addition to MLS, he showed histiocytoid cardiomyopathy and a deteriorating lactic acidosis. To our knowledge, the patient described here is the first MLS case with an X-chromosomal rearrangement other than a terminal deletion or translocation resulting in monosomy of $\mathrm{Xp} 22.3$.

We mapped the telomeric inversion breakpoint in $\mathrm{Xp} 22.32 \sim$ p22.33 to a region of $\sim 500 \mathrm{~kb}$, most likely in intron 1 of ARHGAP6, i.e. our data suggested that the ARHGAP6 gene was disrupted in a portion of the patient's lymphocytes. Several lines of evidence suggest that ARHGAP6 is an attractive candidate gene for MLS syndrome. First, ARHGAP6 is expressed in fetal brain and retina (Schaefer et al., 1997). Various protein isoforms are generated by extensive alternative splicing (Prakash et al., 2000; Kayserili et al., 2001) including three that contain amino acids encoded by exon 1 (GenBank acc. nos. AF012272, AF022212, and AF117067). Expression of a variant in the tissues affected in MLS syndrome would suggest that this isoform plays a role in the normal development and/or function of these organs. However no data exist so far on the tissue-specific expression of these ARHGAP6 transcripts/ isoforms. Second, at least exons 6-16 of ARHGAP6 are deleted in all MLS patients. The proximal boundary of the MLS critical region has been located in intron 1 of ARHGAP6 by defining the deletion breakpoints of the female patient BA325 (Wapenaar et al., 1994) and of the patient described by Kayserili et al. (2001), both presenting with characteristic clinical features of MLS syndrome. In the patient reported here, the mRNAs transcribed from the aberrant $\mathrm{X}$ chromosome would not produce any functional ARHGAP6 variant containing the first 196 amino acids encoded by exon 1 . However, other transcripts with exon 2 as the first exon might be normally expressed from the rearranged $\mathrm{X}$ chromosome. Thus, one can hypothesize that the absence of an ARHGAP6 isoform containing the amino acids encoded by exon 1 is the cause of the MLS syndrome in the patient. Clearly, we can not exclude that another not yet identified gene present on YAC insert $225 \mathrm{H} 10$, possibly located in the $>373-\mathrm{kb}$ intron 1 of ARHGAP6, is implicated in the pathogenesis of MLS syndrome.

The function of ARHGAP6 has been investigated by generating Arhgap6-deficient mice and in vitro expression studies (Prakash et al., 2000). The targeted Arhgap6 allele encodes a putative protein of 470 amino acids that lacks the Rho GAP domain and the C-terminus. Remarkably, loss of Rho GAP function did not cause any detectable phenotypic or behavioural abnormalities in the mutant mice. The N-terminus of ARHGAP6 has been shown to be required for the regulation of cell morphology and actin polymerization (Prakash et al., 2000) and thus, it seems critical for proper ARHGAP6 function. This again indicates that mutated ARHGAP6 isoforms containing an N-terminus encoded by exon 1 may be implicated in MLS syndrome.

Mutation analysis of ARHGAP6 in MLS patients has not been performed because this gene was always included in the terminal Xp22 deletions. Several MLS syndrome patients have been reported with obviously normal karyotypes (Happle et al., 1993; Bird et al., 1994; Cox et al., 1998; Zvulunov et al., 1998; Peter Meinecke, personal communication). However, these patients may carry chromosomal rearrangements that escaped detection by routine cytogenetic analysis. Further studies, including FISH and Southern blot, will help to elucidate the presence of small rearrangements in the above mentioned patients. Finally, mutation screening of ARHGAP6 would be of great interest in cases with no chromosomal rearrangements.

In FISH analysis, YAC $225 \mathrm{H} 10$ produces split signals on the short arm of the rearranged $\mathrm{X}$ chromosome in three metaphases of the patient analyzed suggesting that this YAC spans the breakpoint in the patient. Nonetheless, alternative interpretations of the results obtained are also possible although not very likely. A complex rearrangement might have occurred with a duplication in addition to the inversion. Thus, split signals may result from a duplication comprising (part of) the YAC insert at the proximal inversion breakpoint in $\mathrm{Xp22.2} \mathrm{\sim} \mathrm{p22.13.} \mathrm{Indeed,} \mathrm{characterization} \mathrm{of} \mathrm{an} \mathrm{X/10} \mathrm{translo-}$ 
cation by FISH revealed that, in addition to the translocation, a duplication of at least $500 \mathrm{~kb}$ occurred at the breakpoint region in 10q24 (I. Martinez-Garay and K. Kutsche, unpublished data). Low-copy repeats (LCRs) represent a new class of repetitive DNA element that has been recently identified in the human genome. Intrachromosomal duplications are typically found on a single chromosome or in a single chromosomal band (Mazzarella and Schlessinger, 1998; Ji et al., 2000). Two families of LCRs, CRI-S232 and G1.3 (DXF22S), also known as FAM9 gene family, were found to be interspersed on Xp22.3 (Bardoni et al., 1988; Ballabio et al., 1990; Martinez-Garay et al., 2002). Thus, the presence of a segmental duplication on the short arm of the $\mathrm{X}$ chromosome may also account for the split signals seen in the patient.

The patient had bilateral paranasal linear skin defects but no microphthalmia and thus showed an "incomplete" phenotype of MLS syndrome. Certainly, the mosaicism present in our patient, as in patient 2 described by Lindsay et al. (1994), may have contributed to the milder phenotype. Four female patients with MLS but without microphthalmia have also been reported. Cytogenetic analysis revealed a deletion of Xpter $\rightarrow$ p22.2 in one patient (Allanson and Richter, 1991), a 45,X/ $46, X, \operatorname{del}(X)(p t e r \rightarrow p 22.2)$ mosaicism in the second one (patient 2 in Lindsay et al., 1994), and a normal karyotype in the two remaining cases (patient BA529 in Cox et al., 1998; Zvulunov et al., 1998). Thus, although two patients lacked larger portions of Xp, they did not show the complex phenotype suggesting that the MLS phenotype was not necessarily caused by a larger deletion. Instead, different patterns of $\mathrm{X}$ inactivation may account for the variability of the phenotype. The finding of two karyotypically normal patients (Cox et al., 1998; Zvulunov et al., 1998) suggests that submicroscopic gene defect(s) together with a preferentially inactivated normal X chromosome may also cause the MLS phenotype in females.

The patient presented with severe lactic acidosis, in addition to MLS syndrome. Defects in the pyruvate dehydrogenase (PDH) complex are an important cause of primary lactic acidosis (Lissens et al., 2000). The great majority of PDH complex deficiencies result from mutations in the PDHA1 gene (Dahl et al., 1992; Lissens et al., 2000) which is located in Xp22.2 $\rightarrow$ p22.1 (Brown et al., 1989). PHDA1 encodes the $\alpha$-subunit of the pyruvate dehydrogenase (E1), one of three components of the PDH complex. Remarkably, the proximal inversion breakpoint of the patient was localized to Xp22.2 p22.13 suggesting that the PDHA1 gene could be functionally impaired by the rearrangement.

Somatic mosaicism is becoming increasingly recognized for explaining the phenotype of surviving male patients carrying
X-linked dominant mutations, e.g. in incontinentia pigmenti (IKBKG), Rett syndrome (MECP2), or chondrodysplasia punctata (EBP) (Metzenberg et al., 1999; Clayton-Smith et al., 2000; Armstrong et al., 2001; Kenwrick, 2001; Topçu et al., 2002). We assume that the paracentric inversion of the $\mathrm{X}$ chromosome occurred postzygotically in a particular subset of the patient's cells. Furthermore, it is likely that the inversion was also present in a significant portion of cells of skin, brain, and heart for the patient showed typical features of MLS syndrome, in addition to a histiocytoid/oncocytic cardiomyopathy. Two female patients with MLS syndrome and oncocytic cardiomyopathy (Bird et al., 1994) or hypertrophic cardiomyopathy (Happle et al., 1993) have been reported showing similarities in physical findings and clinical course. Both had normal karotype suggesting that the genetic defect that caused the MLS syndrome might also be implicated in histiocytoid cardiomyopathy. It is of interest to note that the gene for holocytochrome $c$-type synthetase, HCCS, resides in the critical region for MLS syndrome (Schaefer et al., 1996). It has been speculated that a defect of the HCCS enzyme activity could give rise to a nuclear-encoded respiratory chain defect (Schwarz and Cox, 2002) which, in turn, may lead to (histiocytoid) cardiomyopathy in MLS cases. Remarkably, a missense mutation in the mitochondrial cytochrome b (MTCYB) gene was found in a patient with histiocytoid cardiomyopathy (Andreu et al., 2000) suggesting that a mitochondrial respiratory chain enzyme is involved in the pathogenesis of (one form of) this heart phenotype.

To understand the contribution of the genes located in the critical region for MLS syndrome, and in particular that of HCCS, mouse models were created with overlapping deletions similar to the human MLS deletion (Prakash et al., 2002). The complete loss of Hccs leads to embryonic lethality that can be rescued by overexpressing the human HCCS gene from a BAC. These data suggest that male lethality in MLS is caused by deficiency of HCCS (Prakash et al., 2002). The distal inversion breakpoint of the patient maps at least $170 \mathrm{~kb}$ proximal to the $3^{\prime}$ end of HCCS suggesting that this gene is not directly impaired by the chromosomal rearrangement. Although it seems not likely, we cannot exclude with certainty an involvement of the HCCS gene in the phenotypic features of MLS syndrome in the patient. Further studies are required to unravel the role of HCCS and ARHGAP6 in this syndrome.

\section{Acknowledgements}

We thank Arleta Frensel, Janna de Buhr, and Adrian Engel for skillful technical assistance, Vera Kalscheuer for providing us with DOP-PCR products of YAC 225H10, and Gudrun Rappold for cosmids 34F5 and 2.1.

\section{References}

Al-Gazali LI, Mueller RF, Caine A, Antoniou A, McCartney A, Fitchett M, Dennis NR: Two 46,XX,t $(\mathrm{X} ; \mathrm{Y})$ females with linear skin defects and congenital microphthalmia: a new syndrome at Xp22.3. J med Genet 27:59-63 (1990).

Allanson J, Richter S: Linear skin defects and congenital microphthalmia: a new syndrome at Xp22.2. J med Genet 28:143-144 (1991).
Andreu AL, Checcarelli N, Iwata S, Shanske S, DiMauro S: A missense mutation in the mitochondrial cytochrome b gene in a revisited case with histiocytoid cardiomyopathy. Pediatr Res 48:311-314 (2000).

Anguiano A, Yang X, Felix JK, Hoo JJ: Twin brothers with MIDAS syndrome and XX karyotype. Am J med Genet in press (2003).
Armstrong J, Pineda M, Aibar E, Gean E, Monros E: Classic Rett syndrome in a boy as a result of somatic mosaicism for an MECP2 mutation. Ann Neurol 50:692 (2001).

Ballabio A, Andria G: Deletions and translocations involving the distal short arm of the human $\mathrm{X}$ chromosome: review and hypotheses. Hum molec Genet 1:221-227 (1992). 
Ballabio A, Bardoni B, Guioli S, Basler E, Camerino G: Two families of low-copy-number repeats are interspersed on Xp22.3: implications for the high frequency of deletions in this region. Genomics 8:263-270 (1990).

Bardoni B, Guioli S, Raimondi E, Heilig R, Mandel JL, Ottolenghi S, Camerino G: Isolation and characterization of a family of sequences dispersed on the human $\mathrm{X}$ chromosome. Genomics 3:32-38 (1988).

Bartsch O, Wagner A, Hinkel GK, Krebs P, Stumm M, Schmalenberger B, Böhm S, Balci S, Majewski F: FISH studies in 45 patients with Rubinstein-Tayb syndrome: deletions associated with polysplenia hypoplastic left heart and death in infancy. Eur $\mathbf{J}$ hum Genet 7:748-756 (1999).

Bird LM, Krous HF, Eichenfield LF, Swalwell CI Jones MC: Female infant with oncocytic cardiomyopathy and microphthalmia with linear skin defects (MLS): a clue to the pathogenesis of oncocytic cardiomyopathy? Am J med Genet 53:141148 (1994).

Brown RM, Dahl HH, Brown GK: X-chromosome localization of the functional gene for the E1 alpha subunit of the human pyruvate dehydrogenase complex. Genomics 4:174-181 (1989).

Camacho JA, Goodman BK, Hamosh A, Hurko O, Thomas GH: MIDAS syndrome in a 46,XX newborn with ambiguous genitalia and a cryptic, de novo $\mathrm{X} ; \mathrm{Y}$ translocation. Am J hum Genet Suppl 61:A93 (1997).

Clayton-Smith J, Watson P, Ramsden S, Black GC: Somatic mutation in MECP2 as a non-fatal neurodevelopmental disorder in males. Lancet 356:830832 (2000).

Cox TC, Cox LL, Ballabio A: A very high density microsatellite map (1 STR/41 kb) of $1.7 \mathrm{Mb}$ on Xp22 spanning the microphthalmia with linear skin defects (MLS) syndrome critical region. Eur J hum Genet 6:406-412 (1998).

Dahl HH, Brown GK, Brown RM, Hansen LL, Ker DS, Wexler ID, Patel MS, De Meirleir L, Lissens W, Chun K, et al: Mutations and polymorphisms in the pyruvate dehydrogenase E1 alpha gene. Hum Mutat 1:97-102 (1992).

Donnenfeld AE, Graham JM Jr, Packer RJ, Aquino R, Berg SZ, Emanuel BS: Microphthalmia and chorioretinal lesions in a girl with an Xp22.2 $\rightarrow$ pter deletion and partial $3 p$ trisomy: clinical observations relevant to Aicardi syndrome gene localization. Am J med Genet 37:182-186 (1990).

Eng A, Lebel RR, Elejalde BR, Anderson C, Bennett L: Linear facial skin defects associated with microphthalmia and other malformations, with chromosome deletion Xp22.1. J Am Acad Dermatol 31 680-682 (1994).

Ferrero GB, Franco B, Roth EJ, Firulli BA, Borsani G, Delmas-Mata J, Weissenbach J, Halley G, Schlessinger D, Chinault AC, et al: An integrated physica and genetic map of a $35 \mathrm{Mb}$ region on chromosome

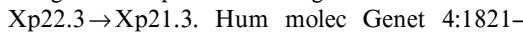
1827 (1995).

Friedman PA, Rao KW, Teplin SW, Aylsworth AS Provisional mapping deletion of the focal dermal hypoplasia (FDH) gene to Xp22.31. Am J hum Genet Suppl 43:A450 (1988).

Gericke GS, Myburgh E, Bester R, van Rensberg EJ, Neethling E: Further delineation of the Xp22.2 $\rightarrow$ pter syndrome of linear skin lesions, microphthalmia and anterior chamber eye anomalies. Am J hum Genet Suppl 49:A271 (1991).

Happle R, Daniels O, Koopman RJ: MIDAS syndrome (microphthalmia, dermal aplasia, and sclerocornea): an X-linked phenotype distinct from Goltz syndrome. Am J med Genet 47:710-713 (1993).

Ji Y, Eichler EE, Schwartz S, Nicholls RD: Structure of chromosomal duplicons and their role in mediating human genomic disorders. Genome Res 10: 597-610 (2000).
Kayserili H, Cox TC, Cox LL, Basaran S, Kilic G, Ballabio A, Yuksel-Apak M: Molecular characterisation of a new case of microphthalmia with linear skin defects (MLS). J med Genet 38:411-417 (2001).

Kenwrick S; The International IP Consortium: Survival of male patients with incontinentia pigmenti carrying a lethal mutation can be explained by somatic mosaicism or Klinefelter syndrome. Am J hum Genet 69:1210-1217 (2001).

Kono T, Migita T, Koyama S, Seki I: Another observation of microphthalmia in an XX male: microphthalmia with linear skin defects syndrome without linear skin lesions. J hum Genet 44:63-68 (1999).

Lagerstrom M, Dahl N, Nakahori Y, Nakagome Y, Backman B, Landegren U, Pettersson U: A deletion in the amelogenin gene (AMG) causes Xlinked amelogenesis imperfecta (AIH1). Genomics 10:971-975 (1991).

Lindor NM, Michels VV, Hoppe DA, Driscoll DJ, Leavitt JA, Dewald GW: Xp22.3 microdeletion syndrome with microphthalmia, sclerocornea, linear skin defects, and congenital heart defects. Am J med Genet 44:61-65 (1992).

Lindsay EA, Grillo A, Ferrero GB, Roth EJ, Magenis E, Grompe M, Hulten M, Gould C, Baldini A, Zoghbi HY, et al.: Microphthalmia with linear skin defects (MLS) syndrome: clinical, cytogenetic, and molecular characterization. Am J med Genet 49:229234 (1994).

Lissens W, De Meirleir L, Seneca S, Liebaers I, Brown GK, Brown RM, Ito M, Naito E, Kuroda Y, Kerr DS, Wexler ID, Patel MS, Robinson BH, Seyda A: Mutations in the X-linked pyruvate dehydrogenase (E1) alpha subunit gene (PDHA1) in patients with a pyruvate dehydrogenase complex deficiency. Hum Mutat 15:209-219 (2000)

Martinez-Garay I, Jablonka S, Sutajova M, Steuernagel P, Gal A, Kutsche K: A new gene family (FAM9) of low-copy repeats in Xp22.3 expressed exclusively in testis: implications for recombinations in this region. Genomics 80:259-267 (2002).

Mazzarella R, Schlessinger D: Pathological consequences of sequence duplications in the human genome. Genome Res 8:1007-1021 (1998).

McLeod SD, Sugar J, Elejalde BR, Eng A, Lebel RR: Gazali-Temple syndrome. Arch Ophthalmol 112: 851-852 (1994)

Metzenberg AB, Kelley R, Smith D, Kopacz K, Sutphen R, Sheffield L, Herman G: Mutations in chondrodysplasia punctata, X-linked dominant type (CDPX2). Am J hum Genet Suppl 65:A480 (1999).

Mücke J, Happle R, Theile H: MIDAS syndrome respectively MLS syndrome: a separate entity rather than a particular lyonization pattern of the gene causing Goltz syndrome. Am J med Genet 57:117118 (1995).

Naritomi K, Izumikawa Y, Nagataki S, Fukushima Y, Wakui K, Niikawa N, Hirayama K: Combined Goltz and Aicardi syndromes in a terminal Xp deletion: are they a contiguous gene syndrome? Am J med Genet 43:839-843 (1992).

Nehls M, Luno K, Schorpp M, Pfeifer D, Krause S, Matysiak-Scholze U, Dierbach H, Boehm T: YAC/ $\mathrm{P} 1$ contigs defining the location of 56 microsatellite markers and several genes across a 3.4-cM interval on mouse chromosome 11. Mammal Genome 6:321-331 (1995).

Ogata T, Wakui K, Muroya K, Ohashi H, Matsuo N, Brown DM, Ishii T, Fukushima Y: Microphthalmia with linear skin defects syndrome in a mosaic female infant with monosomy for the $\mathrm{Xp} 22$ region: molecular analysis of the $\mathrm{Xp} 22$ breakpoint and the $\mathrm{X}$-inactivation pattern. Hum Genet 103:51-56 (1998).
Paulger BR, Kraus EW, Pulitzer DR, Moore CM: Xp microdeletion syndrome characterized by pathognomonic linear skin defects on the head and neck. Pediatr Dermatol 14:26-30 (1997).

Prakash SK, Cormier TA, McCall AE, Garcia JJ, Sierra R, Haupt B, Zoghbi HY, Van Den Veyver IB: Loss of holocytochrome c-type synthetase causes the male lethality of X-linked dominant microphthalmia with linear skin defects (MLS) syndrome. Hum molec Genet 11:3237-3248 (2002).

Prakash SK, Paylor R, Jenna S, Lamarche-Vane N, Armstrong DL, Xu B, Mancini MA, Zoghbi HY: Functional analysis of ARHGAP6, a novel GTPase-activating protein for RhoA. Hum molec Genet 9:477-488 (2000).

Quaderi NA, Schweiger S, Gaudenz K, Franco B, Rugarli EI, Berger W, Feldman GJ, Volta M, Andolfi G, Gilgenkrantz S, Marion RW, Hennekam RC, Opitz JM, Muenke M, Ropers HH, Ballabio A Opitz G/BBB syndrome, a defect of midline development, is due to mutations in a new RING finger gene on Xp22. Nature Genet 17:285-291 (1997).

Schaefer L, Ballabio A, Zoghbi HY: Cloning and characterization of a putative human holocytochrome c-type synthetase gene (HCCS) isolated from the critical region for microphthalmia with linear skin defects (MLS). Genomics 34:166-172 (1996).

Schaefer L, Prakash S, Zoghbi HY: Cloning and characterization of a novel rho-type GTPase-activating protein gene (ARHGAP6) from the critical region for microphthalmia with linear skin defects. Genomics 46:268-277 (1997).

Schwarz QP, Cox TC: Complementation of a yeast CYC3 deficiency identifies an X-linked mammalian activator of apocytochrome c. Genomics 79:5157 (2002).

Stratton RF, Walter CA, Paulgar BR, Price ME, Moore CM: Second 46,XX male with MLS syndrome. Am J med Genet 76:37-41 (1998).

Temple IK, Hurst JA, Hing S, Butler L, Baraitser M: De novo deletion of $\mathrm{Xp} 22.2 \rightarrow$ pter in a female with linear skin lesions of the face and neck, microphthalmia, and anterior chamber eye anomalies. J med Genet 27:56-58 (1990).

Thies U, Rao VV, Engel W, Schmidtke J: Physical mapping of two Xp markers DXS16 and DXS143. Hum Genet 86:418-420 (1991).

Topçu M, Akyerli C, Sayi A, Toruner GA, Kocoglu SR, Cimbis M, Ozcelik T: Somatic mosaicism for an MECP2 mutation associated with classic Rett syndrome in a boy. Eur $\mathrm{J}$ hum Genet 10:77-81 (2002).

Van den Veyver IB: Skewed X inactivation in X-linked disorders. Semin Reprod Med 19:183-191 (2001).

Wapenaar MC, Bassi MT, Schaefer L, Grillo A, Ferrero GB, Chinault AC, Ballabio A, Zoghbi HY: The genes for X-linked ocular albinism (OA1) and microphthalmia with linear skin defects (MLS): cloning and characterization of the critical regions. Hum molec Genet 2:947-952 (1993).

Wapenaar MC, Schiaffino MV, Bassi MT, Schaefer L, Chinault AC, Zoghbi HY, Ballabio A: A YACbased binning strategy facilitating the rapid assembly of cosmid contigs: $1.6 \mathrm{Mb}$ of overlapping cosmids in Xp22. Hum molec Genet 3:1155-1161 (1994).

Werner W, Spiegler AW: Inherited deletion of subband $\mathrm{Xp} 21.13$ in a male with Duchenne muscular dystrophy. J Med Genet 25:377-382 (1988).

Zvulunov A, Kachko L, Manor E, Shinwell E, Carmi R: Reticulolinear aplasia cutis congenita of the face and neck: a distinctive cutaneous manifestation in several syndromes linked to Xp22. Br J Dermatol 138:1046-1052 (1998). 